pp 1542-1565. (C) The Author(s), 2021. Published by Cambridge University Press on behalf of Royal Aeronautical Society. This is an Open Access article, distributed under the terms of the Creative Commons Attribution licence (http://creativecommons.org/licenses/by/4.0/), which permits unrestricted re-use, distribution, and reproduction in any medium, provided the original work is properly cited.

doi:10.1017/aer.2021.25

\title{
Effect of fuels, aromatics and preparation methods on seal swell
}

\author{
A. Anuar \\ Mechanical Engineering Department \\ The University of Sheffield \\ Sheffield \\ UK \\ V.K. Undavalli \\ Institute of Aircraft and Rocket Engines \\ Moscow Aviation Institute (National Research University) \\ Moscow \\ Russia \\ B. Khandelwal \\ bhupendra.khandelwal@gmail.com \\ Mechanical Engineering Department \\ The University of Alabama \\ Tuscaloosa \\ USA

\section{S. Blakey} \\ Mechanical Engineering Department \\ The University of Birmingham \\ Birmingham \\ UK
}

\section{ABSTRACT}

New alternative jet fuels have provided many advantages in the aviation industry, especially in terms of economics and environment. However, fuel-seal compatibility is one of the major issues that restricts alternative fuel advancement into the market. Thus, to help understand and solve the problem, this study examines the swelling effect of prepared and non-prepared 
O-rings in different fuels and aromatic species. Stress relaxation experiments were carried out to evaluate seal compatibility under compression, which mimics engine operation conditions. Seals were compressed and immersed in a variety of fuels and their blends for about $90 \mathrm{~h}$ while maintaining a constant temperature $30^{\circ} \mathrm{C}$ and constant compression force of $25 \%$ seal thickness. The two types of elastomers investigated were fluorosilicone and nitrile O-rings, which are predominantly used in the aviation industry. Meanwhile, three different fuels and aromatic species were utilised as the variables in the experiments. The fuels used were Jet-A1, SPK and SHJFCS, while the aromatic species added were propyl benzene, tetralin and $p$-xylene. The swelling effects were determined from the $\mathrm{P} / \mathrm{P}_{\mathrm{o}}$ value. Results indicate that Jet-A1 has the highest swelling effect, followed by SHJFCS and SPK. It was observed that the higher the percentage of aromatics in fuel, the higher the rate of swelling. Furthermore, prepared seals had a lower swelling rate than did non-prepared seals. Meanwhile, the intensity of the swelling effect in the Jet-A1-SHJFCS blends was in the order of 60/40, 85/15 and 50/50 blend. The work done in this study will aid in the selection of suitable aromatic species in future fuels. The novelty of this research lies in the determination of the appropriate amount of aromatic content as well as the selection of type of aromatic and its mixture fuel. Moreover, the various proportions of fuel blends with aromatic are investigated. The primary aim of this study is to understand the behaviour of prepared and non-prepared seals, and their compatibility with alternative fuels.

Keywords: Seal compatibility; Alternative fuels; Aromatics; Stress relaxation

\section{NOMENCLATURE}

$\begin{array}{ll}\text { AJF } & \text { alternative jet fuels } \\ \text { FT } & \text { Fischer-Tropsch } \\ \text { SPK } & \text { synthetic paraffinic kerosene } \\ \text { EIA } & \text { Energy Information Administration } \\ \text { CTL } & \text { coal-to-liquids } \\ \text { GTL } & \text { gas-to-liquids } \\ \text { BTL } & \text { biomass-to-liquids } \\ \text { GC-MS } & \text { gas chromatography-mass spectrometry } \\ \text { nvPM } & \text { nonvolatile particle emission } \\ \text { H/C } & \text { hydrogen-to-carbon ratio in compound } \\ \text { P/P } & \text { initial force/force } \\ \text { Ni } & \text { nitrile O-ring } \\ \text { Si } & \text { fluorosilicone O-ring } \\ \text { A-SPK-Ni } & \text { prepared nitrile elastomers with acetone in SPK } \\ \text { A-SPK-Si } & \text { prepared fluorosilicone elastomers with acetone in SPK } \\ \text { Tetra } & \text { tetralin } \\ \text { A-Tetra } & \text { acetone-prepared elastomer in tetralin } \\ \text { Pro } & \text { propyl benzene } \\ \text { A-Pro } & \text { acetone-prepared elastomer in propyl benzene } \\ \text { P } & p \text {-xylene } \\ \text { A-P } & \text { acetone-prepared elastomer in } p \text {-xylene } \\ & \end{array}$


Tetra-Pro tetralin and propyl benzene

A-Tetra-Pro acetone-prepared elastomer in tetralin and propyl benzene

Tetra-P tetralin and $p$-xylene

A-Tetra-P acetone-prepared elastomer in tetralin and $p$-xylene

Pro-P propyl benzene and $p$-xylene

A-Pro-P acetone-prepared elastomer in propyl benzene and $p$-xylene

SHJFCS severely hydro-processed jet fuel from conventional source

$50 / 50 \quad 50 \%$ Jet-A1 with $50 \%$ SHJFCS

$60 / 40 \quad 60 \%$ Jet-A1 with $40 \%$ SHJFCS

$85 / 15 \quad 85 \%$ Jet-A1 with $15 \%$ SHJFCS

TC test condition

\subsection{INTRODUCTION}

Fossil fuels are categorised as non-renewable sources of energy. With the depletion of non-renewable sources emerges the need to shift to renewable energy sources. Advancements in the use of sustainable fuels are impacted majorly by the cost increase in crude oil and market fluctuations. Hileman and Stratton ${ }^{(1)}$ outlined the production cost and price of jet fuel from data obtained from the EIA, demonstrating the instability in the price of crude oil. This later leads to a decline in oil production, further aggravating the rise in demand. An even more potential driver for sustainable fuels is growing environmental concern. Considerations over fuels and their emissions lead to the development of renewable fuel and so-called alternative fuels.

New renewable fuels are expected to solve the fuel demands. Types of Alternate Jet Fuels (AJFs) include synthetic and bio jet fuels. Bio jet fuels can be play a role in protecting the climate by reducing $\mathrm{CO}$ and $\mathrm{CO}_{2}$ by using the biowastes as their sources. While on other hand synthetic fuels are chemically produced to be a eco friendly fuel thus by reducing the carbon footprint. In addition to the emission reductions, they offer excellent thermal stability that reduces energy loss. Alternative jet fuels can be made from renewable or non-renewable resources. These fuels are made from the Fischer-Tropsch (FT) process or biological process ${ }^{(2)}$. Synthetic Paraffinic Kerosene (SPK) is derived from the FT process. FT is a process where the synthesis gas that is a mixture of carbon monoxide and hydrogen is converted into higher-molecular-weight hydrocarbon ${ }^{(3)}$. This process can be used with any materials containing carbon. Previously, this process was more expensive than refining petroleum. However, with new technologies, yearly cost reduction has made it more feasible. It has started to be dominant since the increase in demand for synthetic fuel. Some improvements have also been made to this process to increase production with affordable cost.

According to Gregory ${ }^{(3)}$ and Muzzet et al. ${ }^{(4)}$, the Fischer-Tropsch synthesis originated in the early 1920s and 1930s during World War II, produced by the Germans. The first material to undergo the FT process is coal. It results in a by-product of Coal-To-Liquids (CTL). Other materials that are being used in this process are natural gas and biomass, which produce Gas-To-Liquids (GTL) and Biomass-To-Liquids (BTL), respectively. The raw products from FT synthesis are then further processed into suitable jet fuel by breaking the long chain of molecules into smaller molecules. The obtained final products are free from aromatics. The synthetic fuel derived using the FT process is a good alternative fuel. Besides improved thermal stability, it reduces carbon emission. This is because a pure synthetic jet fuel has low or almost no sulphur or aromatic contents. Ewing ${ }^{(2)}$ also emphasised that SPK has very clean 
burning. In addition, fuels derived from the FT process overcome problems of cost and supply faced by petroleum derived fuels.

Despite these advantages, alternative fuels also have some drawbacks, such as poor elastomer compatibility and low density compared with the original jet fuel. Liu and Wilson ${ }^{(5)}$ have also agreed that the compatibility of the alternative fuels with the seals in the turbine engine needs to be prior tested to commercialization. The absence of aromatics in the fuels causes the fuel to have a density below the minimum requirements and makes the seal shrink. This later causes fuel leakage in the engine by degrading rapidly once in contact with the new fuel. The seal shrinking can cause seal failures, thus damaging the system.

Graham et al. ${ }^{(6)}$ and other studies suggested the minimum aromatic content in a fuel is about $8 \%$ on average. This percentage is obtained from vigorous research, but it can go up and down in the future, depending on the types of fuels and aromatics used. It is considered as a safe minimum level of aromatics ${ }^{(1)}$. Besides that, the aromatic content in kerosene ranges from $8 \%$ to $22 \%$. In common jet engine fuel, the high aromatic content encourages the seals to swell, thus providing more protection from leakage. In the case of renewable fuel, the seals tend to extract since it contains no aromatics. These problems can be overcome by adding aromatics to the fuel or by blending it with conventional jet fuels.

The concentrations of aromatics must be minimised to reduce carbon emission ${ }^{(7)}$. Another main purpose of alternative jet fuel production is to have low-sulphur fuels. In addition, it is important for the fuel to have good lubricity for the engine to run smoothly. Other than aromatics, synthetic jet fuel can also be blended with conventional jet fuel to gain the required properties of aviation fuel. The maximum aromatic content is regulated by environmental concerns since aromatics are large contribute to PM emissions. On the other hand, the minimum content was set to improve lubricity and prevent leakage. This is because some chemical contents in conventional jet fuels provide a better swelling effect than that provided by the synthetic fuel-aromatic mixture ${ }^{(8)}$. In this case, new jet fuels can be improved by eliminating or reducing the undesired properties of conventional jet fuels.

Three types of seals frequently being used in the aviation industry are fluorocarbon, fluorosilicone and nitrile seals. These seals are the most common seals found in an aircraft engine. The elastomers, such as O-ring seals, are used mainly in the engine parts and the hydraulic system to prevent leakage. Since the seals are made purely of rubber, they need to be changed after a period. This is because the elastomer starts degrading under different engine conditions. Studies done by Ewing ${ }^{(2)}$ showed that the fluorocarbon showed no degradation or changes when immersed and compressed in a fuel. Therefore, in the current study we used only fluorosilicone and nitrile seals.

According to Liu and Wilson ${ }^{(5)}$, an O-ring is an elastomer which deforms when it is squashed between two parts, thus providing sealing function. Forces are applied when seals are squashed. After a while, the seals are unable to sustain the impact force applied to them. In addition, the long operating hours and fluctuating conditions of the engine apply more impact to the seals. Two effects that commonly happen to the O-ring are swelling and shrinking. In simple terms, swelling can be defined as an increase of seal volume, while shrinking is a decrease in volume. Usually, the swelling of elastomer causes the inner diameter and the thickness of the O-ring to increase. Swelling occurs when an elastomer absorbs some chemical components of fuel, thus softening and swelling. DeWitt et al. ${ }^{(7)}$ explained that the fuel component separation increases as alkanes $<$ alkyl benzenes $<$ naphthalene. Naphthalene is a good hydrogen donor compared with alkyl benzene and alkanes. This is because the alkanes are of nonpolar in nature thus making it a inefficient hydrogen donor, while on otherhand the polarity of alkyl benzene varies, making it also a weak hydrogen donor compared to naphthalene. 
According to Thomas et al. ${ }^{(8)}$, elastomer swelling is an indication of the seal resistance towards the fuel. It can also be described as a chemical attack of the fuels on the elastomers. Meanwhile, Qamar et al. ${ }^{(9)}$ explained swelling as a diffusion process where the fuel hydrocarbon is absorbed by the seal. The acceptable seal swell of the elastomer in the automotive industry is about $12 \%$, while in the aviation industry ranges from $18 \%$ to $30 \%{ }^{(3,6)}$. To further understand the process of swelling, Graham et al. ${ }^{(6)}$ described it thermodynamically as the breaking of the fuel and polymer intermolecular bonds. As a result of this, polymer-fuel bonds are created. The energy required to break the fuel-fuel and polymer-polymer intermolecular bonds is then replaced by the energy released when forming the polymer-fuel bonds. This results in an equilibrium condition, but it also depends on the properties of the fuel and polymer. In addition, Treloar ${ }^{(10)}$ explained that an equilibrium degree of swelling occurs when the cross-linked rubber encounters the low-molecular-weight liquid. The lowmolecular-liquid molecules can easily diffuse into polymers and increase the entropy of the elastomer.

In contrast, shrinking occurs when some molecules or components in the seals are extracted into the fuel, causing the O-ring to degrade. Shrinking makes the seal thinner and the inner diameter smaller. As an example, the absence of plasticisers in the elastomer can cause the O-ring to harden and shrink. Baltrus and Link ${ }^{(11)}$ explained that the shrinking process involves the release of fuel components absorbed by the seals. The components absorbed by the seals can be determined using Gas Chromatography-Mass Spectrometry (GC-MS). It can determine different substances in the sample using the principle of ionisation. Another method to identify the substances in the seals suggested by Baltrus and Link ${ }^{(11)}$ is switch-loading tests.

Aromatic species selection is one of the crucial parts, as it not only affects the elastomer

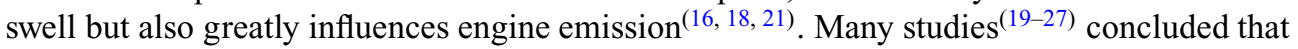
polyaromatic compounds are precursors of Non-Volatile Particle Emission (nvPM). As investigation of aromatic compounds of various types is essential, this study has focussed on three aromatics, that is, tetralin, propyl benzene and $p$-xylene. Tetralin is a polycyclic aromatic, while propyl benzene and $p$-xylene are monocyclic compounds. Polycyclic aromatics have a high $\mathrm{H} / \mathrm{C}$ ratio, thus releasing maximum heat and being a major contributor to emissions compared with monocyclic aromatic compounds ${ }^{(21,24)}$.

The current work contributes to existing research in determining the appropriate amount of aromatic content in the fuel by examining various aromatic percentages, that is, $4 \%, 8 \%$, $12.5 \%$ and $25 \%$. Also, different types of aromatics and mixture fuel are selected. Three aromatics, that is, tetralin, propyl benzene and $p$-xylene, are investigated. In addition to the above blends, various proportions of fuel blends with Jet A-1 of 0/100, 15/85, 40/60, 50/50 and their combination with aromatics are also investigated. The primary aim of the study is to understand the behaviour of acetone-prepared and non-prepared seals, and their compatibility with alternative fuels. This study was carried out by creating engine-like operating conditions for seals under stress.

\subsection{METHODOLOGY}

\subsection{Materials}

In this current study, only fluorosilicone and nitrile O-rings were used in each test since fluorocarbon O-rings do not show significant swelling is and are relatively inert compared with the other two ${ }^{(4)}$. Besides, nitrile and fluorosilicone O-rings are widely used in the market for sealing purposes, especially in the aviation industry ${ }^{(2)}$. Graham et al. ${ }^{(12)}$ also proved that 


\section{Table 1 \\ Specifications of elastomers}
Seals
Part no.
Colour
ID (mm)
CS
Manufacturer
Fluorosilicone
$\begin{array}{cc}\text { L1218 2-113 } & \text { Blue } \\ 100-113-1109 & \text { Black }\end{array}$
$13.94 \pm 0.182 .62 \pm 0.08$ Parker and Haniffin Co.
Nitrile
$13.94 \pm 0.18 \quad 2.62 \pm 0.08$
Trelleborg

(a)

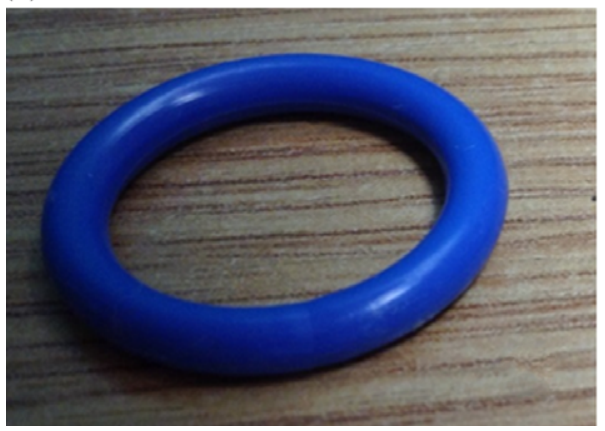

(b)

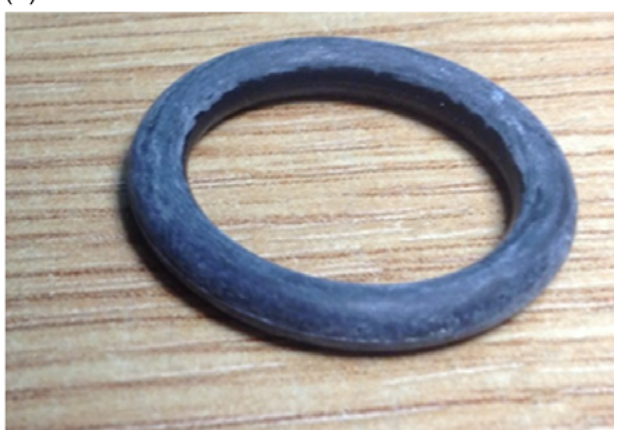

Figure 1. (a) Fluorosilicone and (b) nitrile O-rings.

fluorocarbon elastomer did not exhibit much volume swell compared with nitrile and fluorosilicone. In addition, Ewing ${ }^{(2)}$ verified that fluorocarbon seals showed almost no reaction to swelling. It can be said that the aromatics do not affect fluorocarbon seals. Thus, only nitrile and fluorosilicone seals were studied as described in Table 1 and Fig. 1. The seals used were brand new from sealed package. Fluorosilicone O-rings were obtained from the manufacturer Parker Hannifin Corporation, while nitrile seals were supplied by Trelleborg. Seals in different colours as in Fig. 1 were chosen for easy identification.

\subsection{Fuels and aromatics}

Some of the fuels commonly used in the test are jet propulsion fuel, Shell Sol-T and SPK. The renewable fuels have no or low amount of aromatic content and, thus, act as reference subjects for each study. A wide variety of aromatics was then blended into the fuel with different volume percentages to study the effect of the aromatics towards the volume swell. Graham et al. ${ }^{(12)}$ also blended the aromatics together with the synthetic fuels. Four different tests were conducted in this study to gain a better understanding of seal swell. Besides, these tests helped to determine the concentration of aromatics needed to obtain the desired swelling condition.

Three types of aromatics and three different fuels were used together. The conventional jet fuel, Jet-A1, was used as a reference for this study. The other two fuels used were SPK and Severely Hydro-processed Jet Fuel from Conventional Source (SHJFCS). The SPK made of animal fats was obtained from Shell while the Jet-A1 was from British Petroleum (BP) plc. The aromatics involved were tetralin, propyl benzene and $p$-xylene (Table 2). Tetralin is basically a naphthalene hydrogenated at high pressure with the presence of a catalyst. 


\section{Table 2}

\section{Specifications of aromatics blended with testing fuels}

$\begin{array}{llcc}\text { Aromatics } & \begin{array}{l}\text { Systematic names } \\ \text { (IUPAC name) }\end{array} & \begin{array}{c}\text { Base } \\ \text { compound }\end{array} & \begin{array}{c}\text { Molecule } \\ \text { structure }\end{array} \\ \text { Tetralin, } \mathrm{C}_{10} \mathrm{H}_{12} & \begin{array}{l}\text { 1, 2, 3, 4-Tetrahydronaphthalene } \\ \text { (benzo cyclohexane) }\end{array} & \text { Cyclohexane } & \text { FX1 } \\ p \text {-Xylene, } \mathrm{C}_{8} \mathrm{H}_{10} & \begin{array}{l}\text { 1, 4-Dimethylbenzene } \\ \text { Propyl benzene, } \mathrm{C}_{9} \mathrm{H}_{12}\end{array} & \text { Benzene } & \text { FX2 } \\ \text { 1, } 3 \text { Trimethylbenzene } & \text { Benzene } & \text { FX3 }\end{array}$

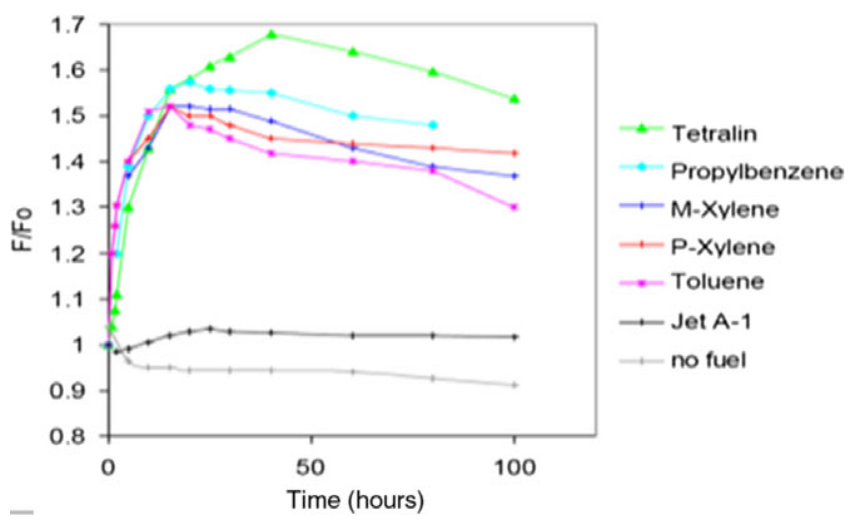

Figure 2. Swelling of O-ring in different pure aromatics by Anderson ${ }^{(13)}$.

These aromatics were chosen based on a study done by Anderson ${ }^{(13)}$. As seen in Fig. 2, tetralin and propyl benzene gave the highest $\mathrm{F} / \mathrm{F}_{\mathrm{o}}$ among the five aromatics tested. The $\mathrm{F} / \mathrm{F}_{\mathrm{o}}$ can be identified as swelling rate. Meanwhile, $p$-xylene showed average swelling rate, but it attained a stable swelling rate after a few hours.

\subsection{Test conditions and fuel blends}

The experiments were conducted over four testing conditions which differed in seal preparation methods and fuel blending. For all four test conditions, swelling effect of O-rings of both fluorosilicone and nitrile were investigated. With regard to seal preparation, non-prepared O-rings were used for test conditions 1, 2 and 4, while prepared O-rings were used for test condition 3. Jet A-1 was used as the reference fuel for all test conditions, while SPK and its blends with the above-mentioned three aromatics were investigated under test conditions 1-3 (Table 3). For convenience in test conditions 1-3, part A of the test condition means that no aromatics are blended in the fuel. Part B means that fuels were blended with multi-species aromatic combinations. Part $\mathrm{C}$ refers to single-species aromatics as presented in Table 3. On other hand, SHJFCS in blending with Jet A-1 fuel is used for test condition 4 as in Table 4.

Test Condition 1 (TC-1) involved the use of SPK with blends of aromatics in $8 \%$ of total fuel volume proportion. This total $8 \%$ aromatic volume included the above-mentioned three 
Table 3

Test conditions of 1-3(TC-1, TC-2, TC-3) and their fuel blends

\begin{tabular}{|c|c|c|c|c|}
\hline \multicolumn{2}{|c|}{ Test materials } & $\begin{array}{c}\text { Test condition } 1 \\
\text { TC-1 }\end{array}$ & $\begin{array}{c}\text { Test condition } 2 \\
\text { TC-2 }\end{array}$ & $\begin{array}{c}\text { Test condition } 3 \\
\text { TC-3 }\end{array}$ \\
\hline \multicolumn{2}{|c|}{ Seal fuels } & $\begin{array}{l}\text { Non-prepared } \\
\text { O-rings of nitrile } \\
\text { and fluorosilicone }\end{array}$ & $\begin{array}{l}\text { Non-prepared } \\
\text { O-rings of nitrile } \\
\text { and fluorosilicone }\end{array}$ & $\begin{array}{l}\text { Acetone-prepared } \\
\text { O-rings of nitrile } \\
\text { and fluorosilicone }\end{array}$ \\
\hline Part A & $\begin{array}{l}\text { Jet A-1 } \\
\text { SPK }\end{array}$ & $\begin{array}{l}100 \% \text { Jet A-1 } \\
100 \% \text { SPK }\end{array}$ & $\begin{array}{l}100 \% \text { Jet A-1 } \\
100 \% \text { SPK }\end{array}$ & $\begin{array}{l}100 \% \text { Jet A-1 } \\
100 \% \text { SPK }\end{array}$ \\
\hline \multirow[t]{3}{*}{ Part B } & SPK & $\begin{array}{l}4 \% \text { Tetralin }+4 \% \\
\text { propyl benzene }\end{array}$ & $\begin{array}{l}12.5 \% \\
\quad \text { Tetralin }+12.5 \% \\
\text { propyl benzene }\end{array}$ & $\begin{array}{l}4 \% \text { Tetralin }+4 \% \\
\text { propyl benzene }\end{array}$ \\
\hline & SPK & $\begin{array}{l}4 \% \text { Tetralin }+4 \% \\
p \text {-xylene }\end{array}$ & $\begin{array}{l}12.5 \% \\
\quad \text { Tetralin }+12.5 \% \\
p \text {-xylene }\end{array}$ & $\begin{array}{l}4 \% \text { Tetralin }+4 \% \\
\quad p \text {-xylene }\end{array}$ \\
\hline & SPK & $\begin{array}{l}4 \% p \text {-Xylene }+4 \% \\
\text { propyl benzene }\end{array}$ & $\begin{array}{l}12.5 \% p- \\
\quad \text { Xylene }+12.5 \% \\
\text { propyl benzene }\end{array}$ & $\begin{array}{l}4 \% p \text {-Xylene }+4 \% \\
\text { propyl benzene }\end{array}$ \\
\hline Part C & $\begin{array}{l}\text { SPK } \\
\text { SPK } \\
\text { SPK }\end{array}$ & $\begin{array}{l}8 \% \text { Tetralin } \\
8 \% \text { Propyl benzene } \\
8 \% \text {-Xylene }\end{array}$ & $\begin{array}{l}25 \% \text { Tetralin } \\
25 \% \text { Propyl benzene } \\
25 \% \text { p-Xylene }\end{array}$ & $\begin{array}{l}8 \% \text { Tetralin } \\
8 \% \text { Propyl benzene } \\
8 \% \text {-Xylene }\end{array}$ \\
\hline
\end{tabular}

Table 4

Fuel blends in volumetric proportion for test condition 4 (TC-4)

$\begin{array}{lccccc}\text { Fuel } & \mathbf{0 / 1 0 0} & \mathbf{5 0 / 5 0} & \mathbf{6 0} / \mathbf{4 0} & \mathbf{8 5} / \mathbf{1 5} & \mathbf{1 0 0 / 0} \\ \text { Jet-A1 } & 0 \% & 50 \% & 60 \% & 85 \% & 100 \% \\ \text { SHJFCS } & 100 \% & 50 \% & 40 \% & 15 \% & 0 \%\end{array}$

aromatics in various proportions and combinations as presented in Table 3. Under TC-1, we evaluated the swelling effect of O-rings with minimum aromatic content required for swelling promotion $^{(6-8,12,13)}$. Under Test Condition 2 (TC-2), total aromatic volume increased to $25 \%$ from minimum aromatic content $8 \%$. The $4 \%$ of individual aromatic species increased to $12.5 \%$, while the $8 \%$ of individual aromatic species was increased to $25 \%$ mixture (Table 3 ). TC-2 was carried out using the same O-rings from TC-1, and no new O-rings were utilised in this part to observe their reaction towards increasing aromatic content. Meanwhile, Test Condition 3 (TC-3) compared the swelling effect of O-ring with different preparation methods. In this test, the O-rings were prepared with acetone and tested with the same fuel mixtures of TC-1 (Table 3). The results were then compared with TC-1 to determine the effect of the preparation method. On the other hand, Test Condition 4 (TC-4) evaluated the swelling effect of the elastomers in SHJFCS, Jet-A1, and blends of SHJFCS and Jet-A1 (Table 4). In this part, no aromatics were involved. TC-4 was conducted to find the optimum blend ratio of the SHJFCS and Jet-A1. 

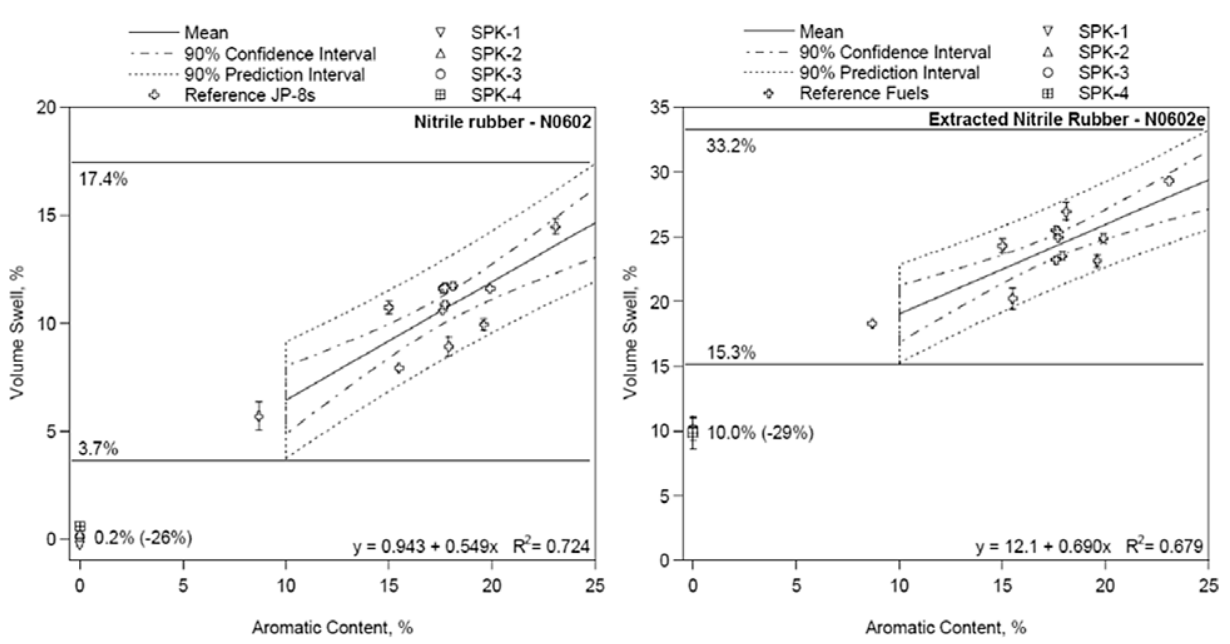

Figure 3. Comparison of swelling effect with different preparation methods by Graham et al. ${ }^{(6)}$.

\subsection{O-ring preparation}

In TC-3, the swelling effect of the O-ring was compared on the basis of its preparation method. The first, second and fourth test condition were conducted with non-prepared elastomer using the new O-ring. Only the elastomers for third test condition were prepared in the manners suggested by Graham et al. ${ }^{(6)}$. The elastomers were soaked in acetone for a whole day. Afterwards, they were rinsed with acetone three times. Before oven drying at a constant temperature of $60^{\circ} \mathrm{C}$, the seals were air dried for 1 day. The function of this preparation method is to de-plasticise the elastomer. In other words, the plasticiser of the elastomer is removed from its surfaces. Since the elastomers in a jet or airplane are not new, this preparation method enables researchers to visualise the used elastomer instead of the new one. Thus, it gives better representations of O-rings which are in service. It was also explained by Graham et al. ${ }^{(6)}$ that the extraction of plasticiser is crucial since it tends to depress the swelling effect of the O-ring material. The swelling effect for different preparation methods can be seen in Fig. 3 .

\subsection{Equipment setup}

The tests were conducted using the Relaxation Rig System EB02 made by Elastocon AB (Fig. 4). Four rigs can be placed and run simultaneously in the cell oven. The temperature in each rig can also be set differently. The stress relaxation system was used to study seal compatibility under different conditions of either tension or compression. Different standards of regulation must be used when using tension or compression. The load cells and rig temperature sensors were calibrated to function precisely. These parts were then connected to the data connection box to enable data recording of the rig temperature and force exerted by the O-ring. The dial gauge was also checked for any faults.

Stress relaxation test was chosen as the sole procedure in this project because it uses an ageing effect that helps to shorten the operating hours while providing much information ${ }^{(14)}$. The continuous measurement system also helps to record the data at a desired time range of seconds, minutes or hours. In this project, the test procedure was followed on the basis of the standard ISO 3384-1. Since this study focuses mainly on compression, the stress relaxation in tension using standard ISO 6914 was not considered. All the results were taken continuously 


\section{Table 5 \\ Aromatic species properties}

$\begin{array}{lccc}\text { Aromatics } & \begin{array}{c}\text { Molar mass } \\ \mathbf{( k g / m o l})\end{array} & \begin{array}{c}\text { Density, } \boldsymbol{\rho} \\ \left(\mathbf{k g} / \mathbf{m}^{\mathbf{3}}\right)\end{array} & \begin{array}{c}\text { Molar volume, } \\ \mathbf{V}_{\mathbf{m}}(\mathbf{m l} / \mathbf{m o l})\end{array} \\ \text { Tetralin, } \mathrm{C}_{10} \mathrm{H}_{12} & 0.1322 & 973 & 135.7 \\ p \text {-Xylene, } \mathrm{C}_{8} \mathrm{H}_{10} & 0.10617 & 860 & 122.6 \\ \text { Propyl benzene, } \mathrm{C}_{9} \mathrm{H}_{12} & 0.12019 & 862 & 139.1\end{array}$

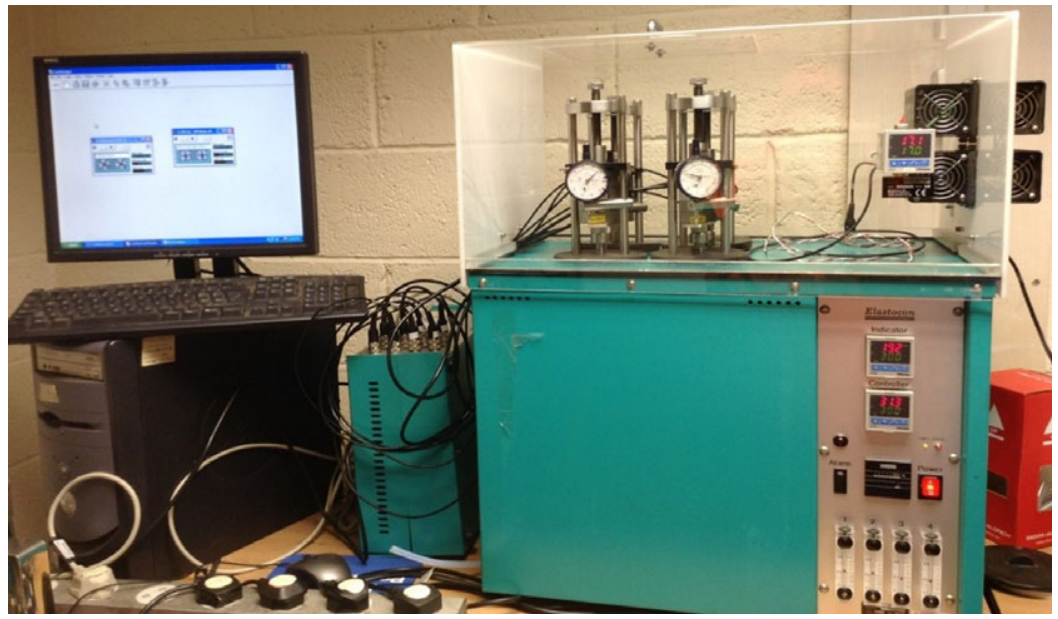

Figure 4. Stress relaxation system.

at every hour until $90 \mathrm{~h}$. The analysis was done by determining the initial force applied to the seal at zero hours. After $1 \mathrm{~h}$, the new force, better known as the counterforce, was recorded. To determine the swelling response of the seal, the force at a given time that is the counterforce was divided with the initial force giving $\mathrm{P} / \mathrm{P}_{0}$, as in equation $1^{(17)}$. The ratio of the counterforce to the initial force determines the rate of swelling of the elastomer at a given time. Swelling of the $\mathrm{O}$-ring occurs if $\mathrm{P} / \mathrm{P}_{\mathrm{o}}$ exceeded the value of 1 , while shrinking happens if it is less than 1 . The shrinking of the seals is caused by the extraction of the elastomers into the fuel.

$$
\text { Swell Rate }=\frac{\text { Force, } P}{\text { Initial Force, } P_{o}}=\frac{P}{P_{o}}
$$

\subsection{RESULTS AND DISCUSSION}

To determine the swelling effect, the $\mathrm{P} / \mathrm{P}_{\mathrm{o}}$ values were calculated from the data. The higher the $\mathrm{P} / \mathrm{P}_{\mathrm{o}}$ value, the higher the swelling effect of the elastomer. According to Graham et al. ${ }^{(12)}$, the smaller the size or molar volume of the aromatic, the higher the rate of seal swelling. It can be referenced that the greatest seal swelling occurs in fuel and aromatics with small molar volume and strong hydrogen bonding potential and polarity ${ }^{(7)}$. Table 5 lists the properties of 


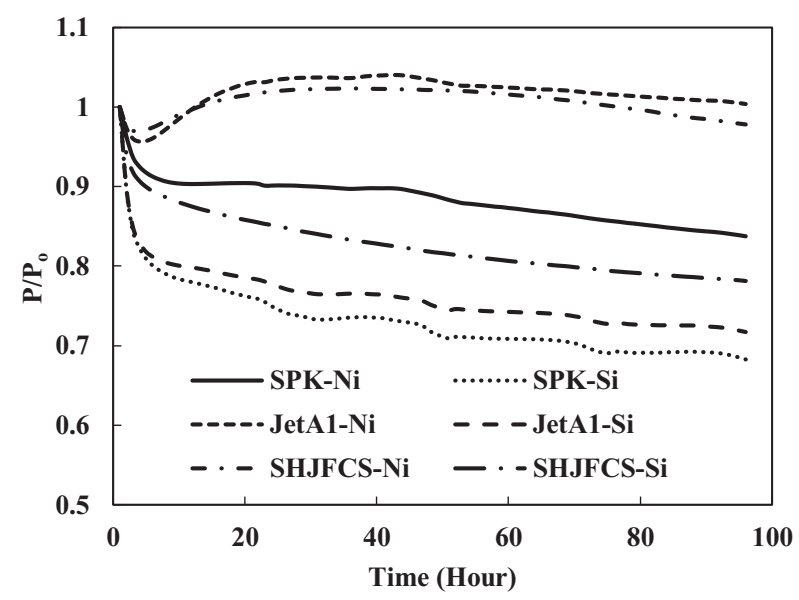

Figure 5. O-ring swell in SPK, Jet-A1 and SHJFCS with no added aromatics.

aromatics used in this study. The molar volume of each aromatic can be calculated using Equation 2, which depends on its base compound ${ }^{(15)}$ :

$$
V=V_{b}+K(N-n)
$$

where

$$
\begin{aligned}
& V=\text { molar volume of compound } \\
& K=2.696 \\
& V_{\mathrm{b}}=\text { molar volume of base compound } \\
& N=\text { outer electron compound } \\
& n=\text { outer electron base compound }
\end{aligned}
$$

As discussed in methodology, the results will be presented as follows. We will discuss the results of test conditions 1-3 in a stage-wise manner of part A, part B and part C, followed by test condition 4 .

\subsection{Results of SPK, SHJFCS and Jet-A1 with no added aromatics}

The swelling effect of nitrile and fluorosilicone O-rings in Jet-A1, SPK and SHJFCS with no added aromatics was compared (Fig. 5). Results show that the SHJFCS gave almost the same swelling effect as did Jet-A1 for nitrile O-rings. The high concentration of aromatics in Jet-A1 caused the swell rate of SHJFCS to be slightly lower than that of Jet-A1. Since there are no aromatics in SPK, neither elastomer immerged in SPK exhibited swelling; the nitrile O-ring exhibited swelling only in Jet-A1 and SHJFCS. The nitrile O-ring in Jet-A1 fuel started to swell in the fifth hour, almost the same time as that in SHJFCS fuel. The 5h delay in swelling was due to the chemical components being extracted from the fuel before swelling. This is different from O-rings immersed in SPK where, due to the absence of aromatics, extraction was followed by further shrinking. In Fig. 5 it is clear that the fluorosilicone seals shrank dramatically at the beginning of the test and further extracted until the end point. The shrinkage of seals in SHJFCS was not severe, unlike that of fluorosilicone seals in Jet-A1 and SPK. It can be said that the SHJFCS tried to maintain the elastomer condition by reducing the shrinkage process. The results show that the maximum $\mathrm{P} / \mathrm{P}_{\mathrm{o}}$ value for nitrile in SPK is 1 . 


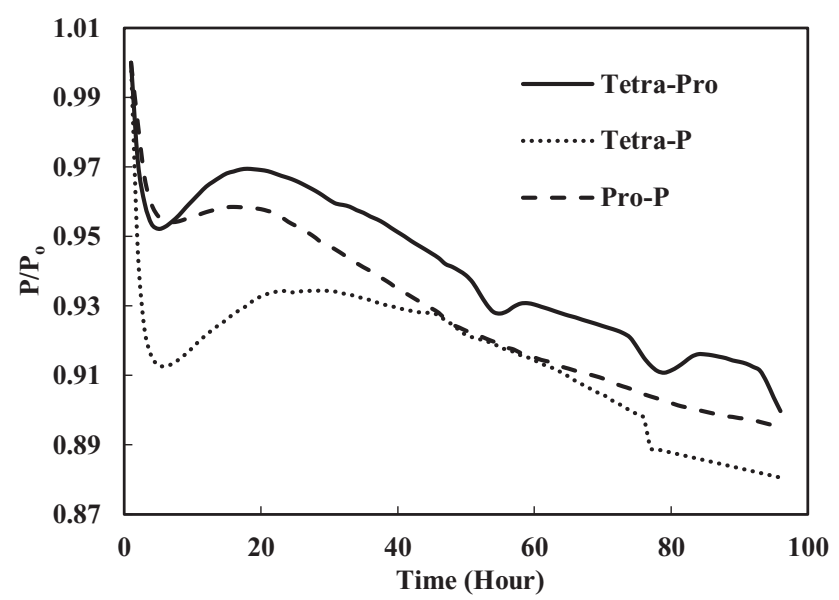

Figure 6. Nitrile O-ring swell in multi-species aromatics (4\% each) blended in SPK.

This can be compared with the results in Fig. 5, showing only the extraction of nitrile seal in SPK during the whole test. It can be said that Jet-A1 and SHJFCS have their own aromatics that encourage the swelling of the O-ring, unlike SPK.

\subsection{Results of SPK with minimum content of aromatics ( $8 \%$ volume) for TC-1}

\subsubsection{SPK with multi-species aromatics of 4\% each (TC-1 part B)}

Here, SPK fuel is blended with two different aromatic species of $4 \%$ each to obtain an overall aromatic content of $8 \%$ fuel. This is the minimum prescribed aromatic content required in a fuel to promote seal swell ${ }^{(6-8,12,13)}$. As seen in Fig. 6, the $\mathrm{P} / \mathrm{P}_{\mathrm{o}}$ value for each component does not exceed 1. However, swelling did occur for all nitrile O-rings because a slight bump or increase in $\mathrm{P} / \mathrm{P}_{\mathrm{o}}$ values can be seen in Fig. 6 .

Since the extraction of the elastomer occurred in at bigger value compared with swell, the swelling rate did not exceed the value of 1 . For nitrile O-rings, the biggest swelling effect occurred in the fuel mixture of SPK with tetralin and propyl benzene, while the smallest occurred in the fuel mixture of SPK with $p$-xylene and propyl benzene. The nitrile seal in tetralin and propyl benzene has a higher swelling rate compared with the other two (Fig. 6). Instead of molar volume, seal swelling in tetralin-propyl benzene blend was highly affected by the hydrogen bonding potential of those two aromatics. Tetralin shares characteristics with the naphthalene group, and propyl benzene with benzene group. According to DeWitt et al. ${ }^{(7)}$, the polarity of alkyl naphthalene shows stronger variation than that of benzene, thus making it easier for it to be a hydrogen donor. Therefore, the fuel-fuel bond will be broken easily, thus encouraging swelling to occur.

Figure 7 shows that no swelling was observed for fluorosilicone O-rings in all the above three fuel mixtures. Unlike nitrile, the biggest swelling effect of fluorosilicone O-ring occurred in the SPK mixture of propyl benzene and $p$-xylene. This is because the role of polarity, molar volume and hydrogen bonding potential in swelling is only dominant in nitrile O-rings. Since rate of swelling depends on various factors, only the net factors of volume swell must be considered. It can also be seen that the maximum values of $\mathrm{P} / \mathrm{P}_{\mathrm{o}}$ for all the $4 \%$ fuel mixtures were the same and occurred at the starting point. 


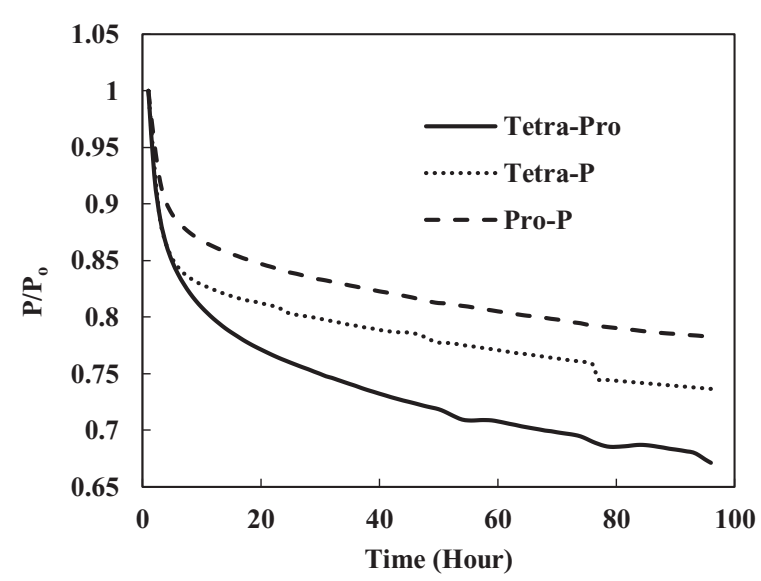

Figure 7. Fluorosilicone O-ring swell in multi-species aromatics (4\% each) blended in SPK.

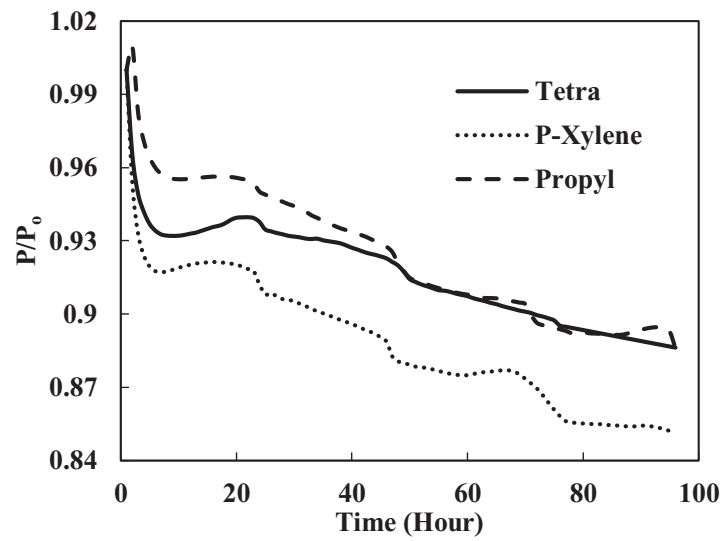

Figure 8. Nitrile O-ring swell in single-species aromatics ( $8 \%$ vol) blended in SPK.

\subsubsection{SPK with single-species aromatics of $8 \%$ (TC-1 part C)}

Here, fuel is blended with single-species aromatic with $8 \%$ aromatic content. Swelling was observed at all the nitrile O-rings in the three fuel mixtures. However, as seen in Fig. 8, the swell is too small compared with the shrinking of the nitrile seals. Besides, only nitrile O-rings soaked in propyl benzene started with swelling while others started with extraction. On the other hand, no swelling occurred for fluorosilicone O-rings in all three mixtures of tetralin, $p$-xylene and propyl benzene with SPK (Fig. 9). Meanwhile, the maximum $\mathrm{P} / \mathrm{P}_{\mathrm{o}}$ obtained by the nitrile O-ring was the highest in propyl benzene mixture, followed by tetralin and $p$-xylene. It can be said that, for $8 \%$ aromatic blends, both the hydrogen bonding potential and molar volume play a role in affecting the swell rate, because the lowest swelling effect was for seal in $p$-xylene, which has the lowest molar volume but weakest hydrogen bonding potential. To achieve a good swell, the aromatics should have small molar volume and high 


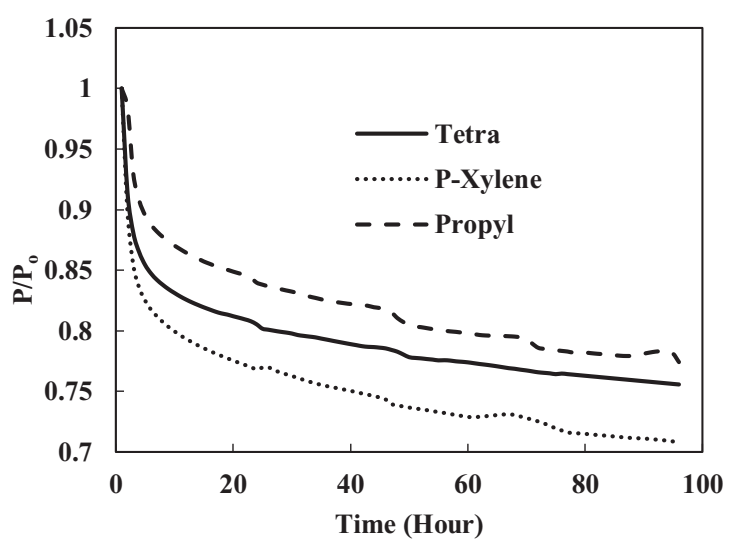

Figure 9. Fluorosilicone O-ring swell in single-species aromatics (8\% vol) blended in SPK.

hydrogen bonding potential. The tetralin and $p$-xylene mixtures only achieve the maximum $\mathrm{P} / \mathrm{P}_{\mathrm{o}}$ value of 1 at the start of the test (Figs. 8 and 9) because the rate of extraction is greater than the rate of swelling.

\subsection{TC-2: SPK with increased aromatic content of $25 \%$ volume in fuel}

There was little improvement of swelling in the TC-1 with minimum aromatic content of $8 \%$, encouraging us to understand the behaviour of swelling at elevated aromatic contents. So, in TC-2, the $4 \%$ multi-species aromatics of TC- 1 were increased to $12.5 \%$ and $8 \%$ single-species aromatics of TC-1 to $25 \%$ in SPK, thus attaining overall aromatic content of $25 \%$ for all the fuel blends of TC-2.

\subsubsection{SPK with multi-species aromatics of $12.5 \%$ each (TC-2 part B)}

Since minimum aromatic content $8 \%$ had not shown a big increase in swelling, the aromatic contents were increased with the purpose of achieving significant volume swell of the seals. The volume percentage of each aromatic species was increased from $4 \%$ to $12.5 \%$ to increase the total volume percentage to $25 \%$. The same elastomers were used to give accurate results. The results from different fuels and aromatics were then compared (Figs. 10 and 11). As seen in Fig. 10, only nitrile O-rings swelled, while there was no swelling for fluorosilicone seals. A better explanation of the swelling effect of the nitrile O-ring is shown in Fig. 11. The nitrile O-rings in three different fuel mixtures started with extraction but then swelled greatly before extraction took place once again. The greatest swelling effect occurred to nitrile O-ring in propyl benzene and $p$-xylene mixture with SPK. On the other hand, the rate of seal swelling in tetralin and propyl benzene was the lowest because it has the biggest molar volume, with a size of $275.4 \mathrm{ml} / \mathrm{mol}$. This makes it harder for fuel components to diffuse into O-rings, hence the observed lower swelling effect. Fluorosilicone O-rings followed the same trend.

For fluorosilicone O-rings, no significant swells occurred (Fig. 11). The highest maximum value of $\mathrm{P} / \mathrm{P}_{\mathrm{o}}$ was also obtained by the nitrile $\mathrm{O}$-ring in the mixture of propyl benzene and $p$-xylene. The maximum $\mathrm{P} / \mathrm{P}_{\mathrm{o}}$ value for fluorosilicone seals was only 1 , while other nitrile O-rings achieved the maximum value of $\mathrm{P} / \mathrm{P}_{\mathrm{o}}$ with a value greater than 1 . 


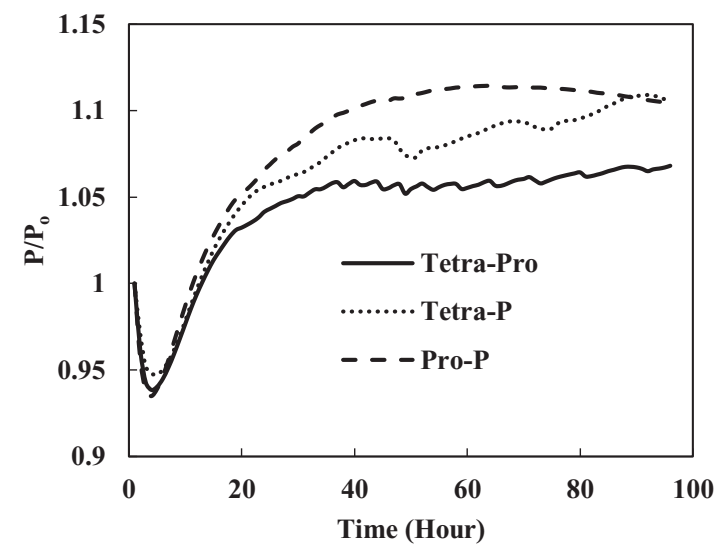

Figure 10. Nitrile O-ring swell in multi-species aromatics (12.5\% each) blended in SPK.

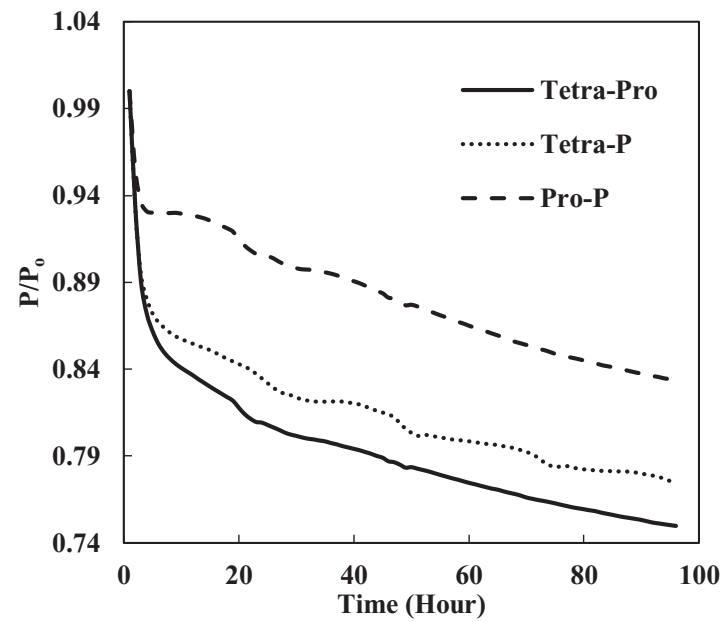

Figure 11. Fluorosilicone O-ring swell in multi-species aromatics (12.5\% each) blended in SPK.

\subsubsection{SPK with single-species aromatics of $25 \%$ vol (TC-2 part C)}

Here, the fuel SPK was blended with single-species aromatics of $25 \%$ in volume. Figs. 12 and 13 show that the swelling occurred at all nitrile seals, while the fluorosilicone O-ring in propyl benzene mixture with SPK exhibited a small swelling. The nitrile seals in Fig. 12 show that they went through small extraction at the beginning, followed by great swelling.

Figure 12 shows that seal in tetralin blend had the highest rate of swelling. Since tetralin is derived from the naphthalene group, it is expected to have seal swell higher than the benzene group of propyl benzene and $p$-xylene. This is because the naphthalene group has higher potential to be a hydrogen donor, thus encouraging swelling to occur. It has been observed by other researchers as well that hydrogen bonding of components of fuels can play a major role in seal swell phenomenon. On the other hand, all fluorosilicone seals in Fig. 13 went through extraction, except for seal in propyl benzene where it had slight swelling with the value of 


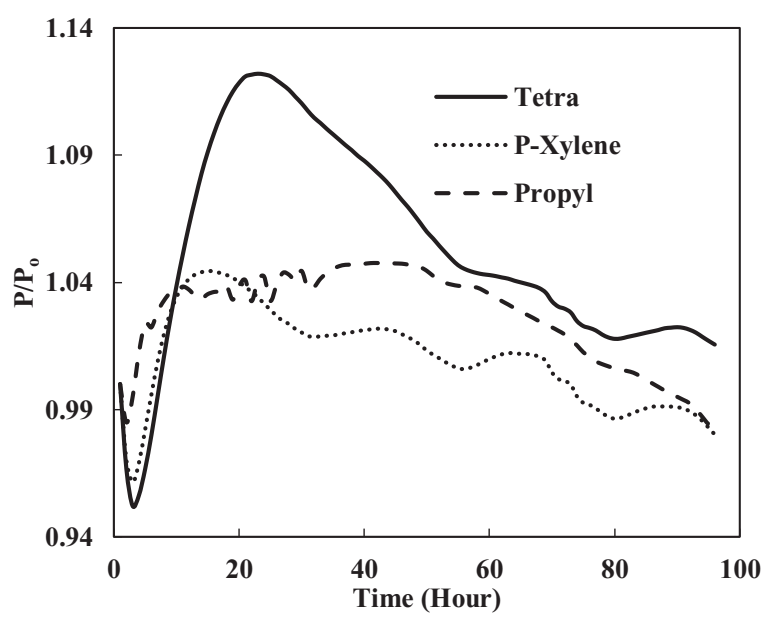

Figure 12. Nitrile O-ring swell in single-species aromatics (25\% vol) blended in SPK.

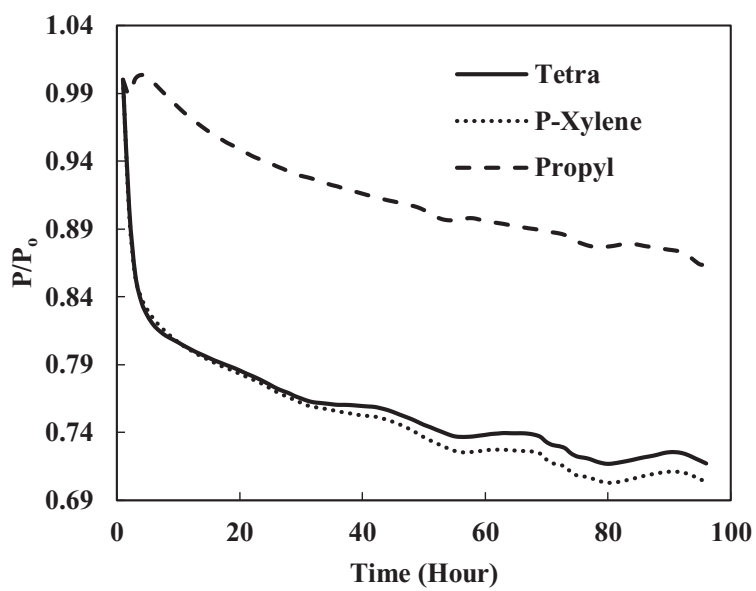

Figure 13. Fluorosilicone O-rings swell in single-species aromatics ( $25 \%$ vol) blended in SPK.

1.003539. The highest maximum $\mathrm{P} / \mathrm{P}_{\mathrm{o}}$ value was obtained by the nitrile $\mathrm{O}$-ring in the tetralin mixture.

\subsection{Comparison of results for TC-1 and TC-2}

The TC- 1 and TC-2 conditions were compared. Part B of TC-1 (4\% each) and TC-2 (12.5\% each) and part $\mathrm{C}$ of TC-1 (8\% vol) and TC-2 (25\% vol) are discussed below. As shown in Fig. 14 and Fig. 16, the swelling effect was only significant for the O-rings in $12.5 \%$ each and $25 \%$ mixtures of aromatics and SPK. The seals in $4 \%$ each and $8 \%$ mixtures of aromatics and SPK did not show a big swelling effect, indicating that the aromatic content does affect the swelling of O-rings and that increasing overall aromatics would promote the swelling.

In Figs. 15 and 17, it can be seen clearly that the increase in aromatic percentage from 4\% to $12.5 \%$ and $8 \%$ to $25 \%$ increases the swelling for nitrile seals. Meanwhile, the extraction 


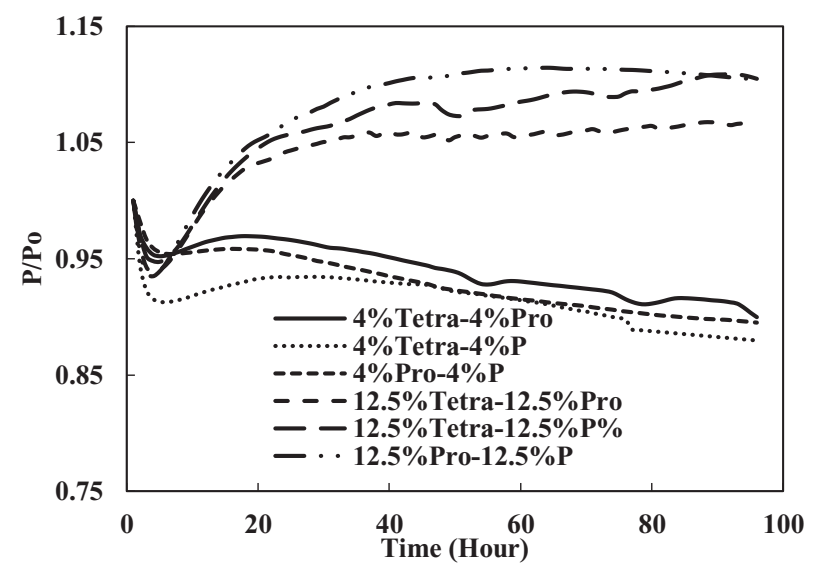

Figure 14. Effect of multi-species aromatic content increment from $4 \%$ each to $12.5 \%$ each for nitrile O-ring.

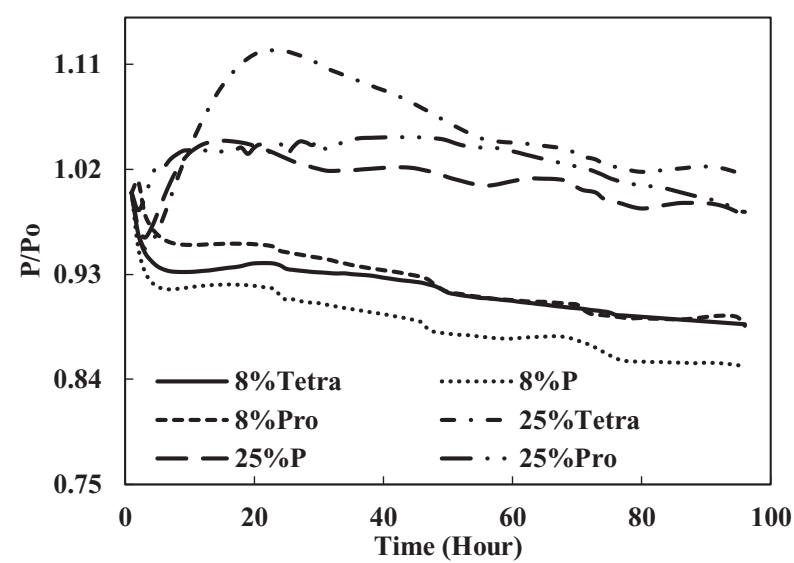

Figure 15. Effect of multi-species aromatic content increment from $8 \%$ each to $25 \%$ each for nitrile O-ring.

for fluorosilicone seals decreases as the percentage of aromatics increases from $4 \%$ to $12.5 \%$ and $8 \%$ to $25 \%$.

The results are plotted in Figs. 15 and 17 compared to Figs. 14 and 16, showing that the percentage increase of aromatics causes an increase in swelling rate and decrease in extraction rate. In addition, the mixture of different types of aromatics in fuels also affects the results.

\subsection{TC-3: effect of seal preparation and its comparison with TC-1}

TC-3 assessed the seal preparation methods and their effects on seals swelling. Unlike other tests, this test used prepared O-rings. The preparation involved washing and rinsing of O-rings using acetone as discussed in section 2.4. Four comparisons were made between the prepared (TC-3) and non-prepared (TC-1) seals immersed in SPK, Jet-A1, 4\%+4\% multi-species aromatics with SPK and 8\% single-species aromatics with SPK. As seen in Fig. 18, the nonprepared seals (e.g. SPK-Ni) have a higher rate of swelling than do the acetone-prepared seals 


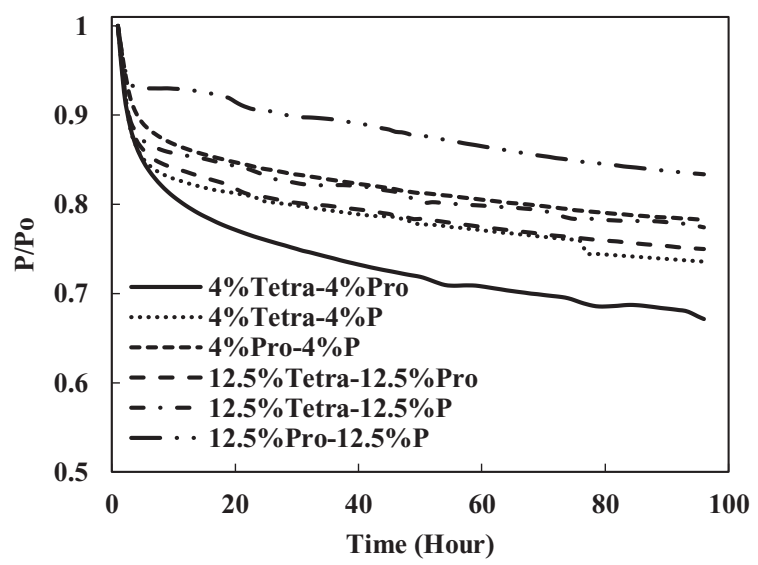

Figure 16. Effect of multi-species aromatic content increment from $4 \%$ each to $12.5 \%$ each for fluorosilicone O-ring.

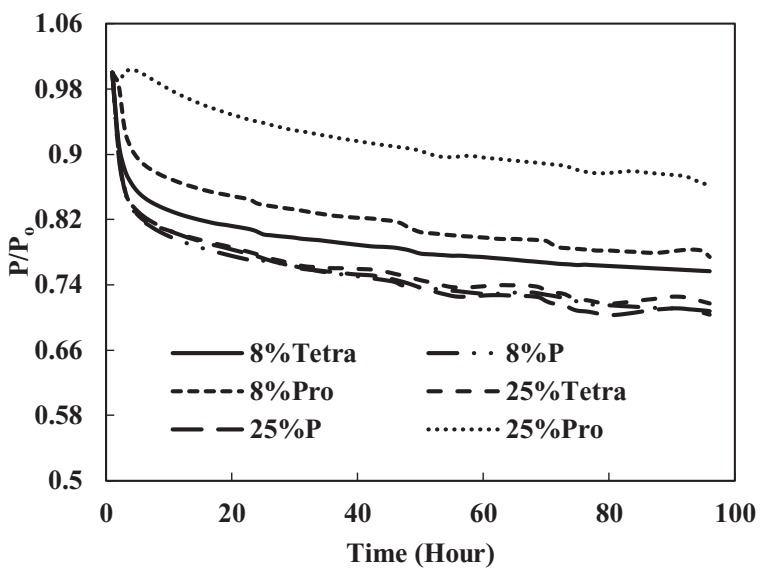

Figure 17. Effect of multi-species aromatic content increment from $8 \%$ each to $25 \%$ each for fluorosilicone O-ring.

(e.g. A-SPK-Ni). This is true regardless of fuels and aromatics and is particularly obvious for nitrile seals (Figs. 19 and 21).

This happens because the prepared seals lose their plasticisers once they were washed and rinsed with acetone. Plasticiser is the main element of elastomers that makes them flexible. Once the plasticisers are gone, the seals will harden and later shrink. It was also in agreement with the test results obtained by Ewing ${ }^{(2)}$ where the seals lost $10-15 \%$ of their original volume when they lost their plasticisers, and the seals also shrank as a result of this.

Figure 19 shows a comparison of nitrile elastomers with and without preparation. The greatest relaxation was noted for the aromatic mixture of $4 \%$ propyl benzene and $4 \% p$-xylene in SPK fuel for a prepared nitrile elastomer. In contrast, the least relaxation was observed in non-prepared seals $4 \%$ propyl benzene and $4 \% p$-xylene. This clearly shows the effect of seal preparation and rate of strain inherited with method of preparation. On the other hand, as shown in Fig. 22, the fluorosilicone seals showed little difference in the swelling rate between 


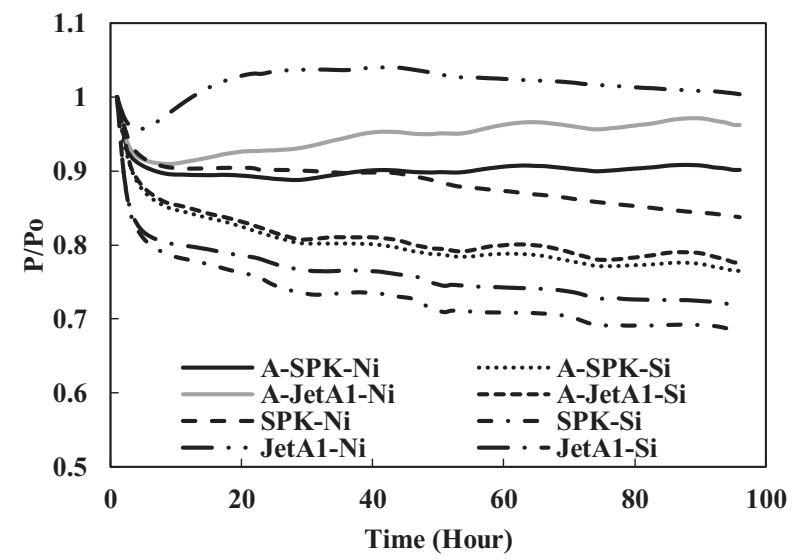

Figure 18. Swelling effect of acetone-prepared (A-) and non-prepared O-rings in Jet-A1 and SPK with no aromatics added.

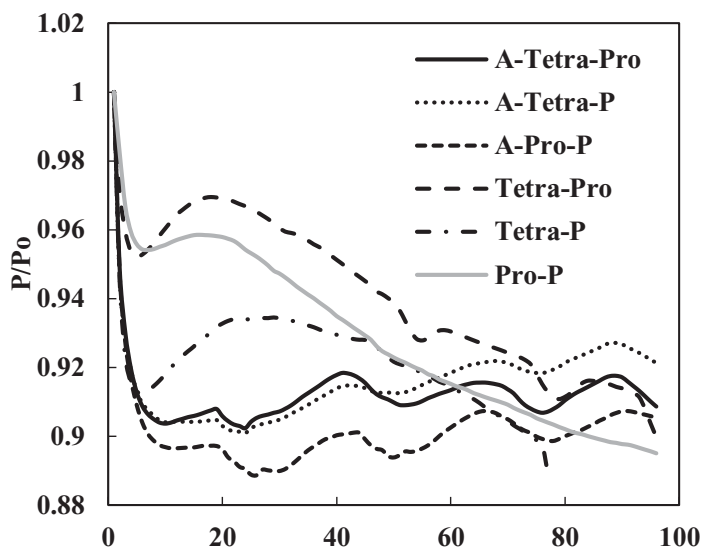

Figure 19. Swelling effect of acetone-prepared (A-) and non-prepared nitrile O-rings in SPK fuel blends of multi-species aromatic with $4 \%$ vol each.

the prepared and non-prepared seals. However, the non-prepared seals had low extraction value compared with the prepared seals. This means that the plasticisers in the non-prepared O-rings may still potentially facilitate swelling (Fig. 20). Only extraction occurs at all of the fluorosilicone O-rings, whereas swelling is not significant.

To identify the magnitude of swelling and effect of aromatics on prepared seals, the aromatic content was further increased to $8 \%$. Along with this increment, only a particular aromatic species was blended to $8 \%$ fuel to identify the effect of individual aromatic species on prepared and non-prepared seals (Figs. 21 and 22). For nitrile elastomers, as shown in Fig. 21, the greatest relaxation was observed from the $p$-xylene aromatic species for an acetone-prepared elastomer, while the least relaxation was observed in non-prepared seal with propyl benzene aromatics. On comparing the results in Figs. 19 and 20 of nitrile seals, it is evident that with increase in aromatic content there is greater relaxation, and thus a greater 


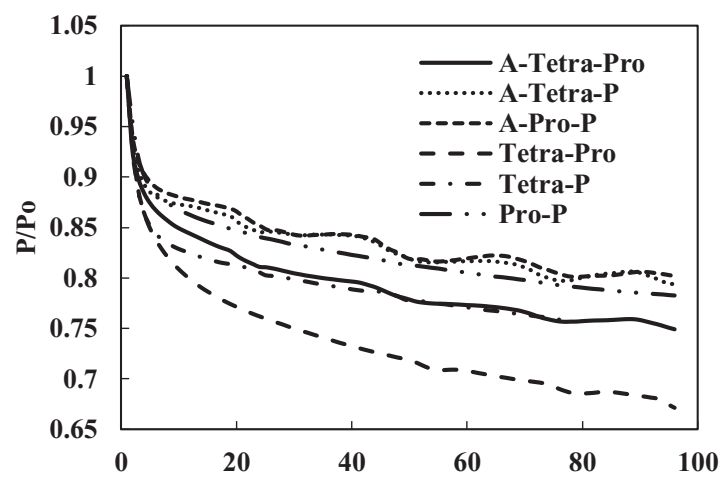

Figure 20. Swelling effect of acetone-prepared (A-) and non-prepared fluorosilicone O-ring in SPK fuel blends of multi-species aromatic with $4 \%$ vol each.

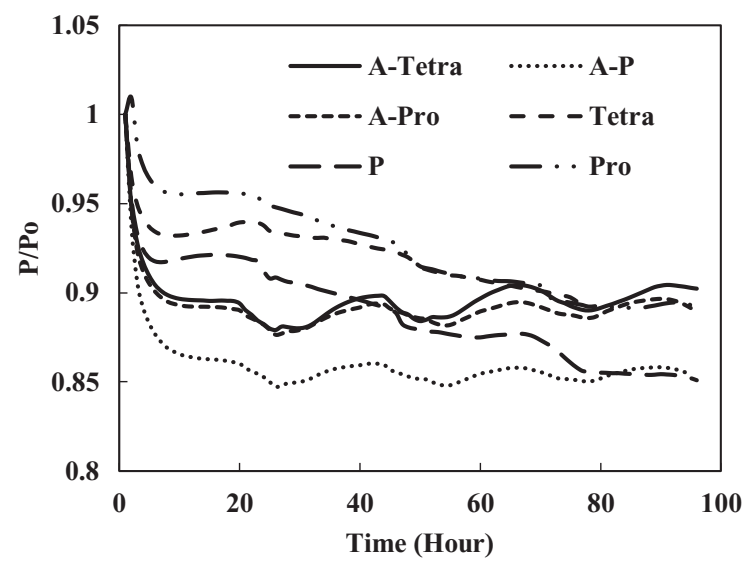

Figure 21. Swelling effect of acetone-prepared (A-) and non-prepared nitrile O-rings in SPK fuel blends of single-species aromatics with $8 \%$ vol.

swell. As Figs. 19 and 20 show, the least relaxation force was on the order of 0.88 and 0.85 for the same elastomer.

From the results of fluorosilicone elastomer, as shown in Fig. 22, plasticisers in the nonprepared O-rings may still facilitate swelling with increment in aromatic content to $8 \%$, where a similar behaviour was exhibited for $4 \%$ aromatic content. Only extraction occurred at all the fluorosilicone O-rings, while swelling was not significant. The graphs also clearly illustrate the differential magnitude of swelling for a prepared and non-prepared seal. This work has shown the importance of proper preparation before any detailed analysis and testing is done on different types of O-rings and fuel components. If appropriate care is not taken, there is a risk of generating results that are different in scales.

\subsection{TC-4: blends of Jet-A1 and SHJFCS}

The fourth test condition (TC-4) compared the swelling effect of elastomers of different composition of Jet-A1 and SHJFCS. The aim of this test condition was to obtain an optimal blend ratio of conventional Jet A-1 fuel with FT derived fuels and their compatibility effects. 


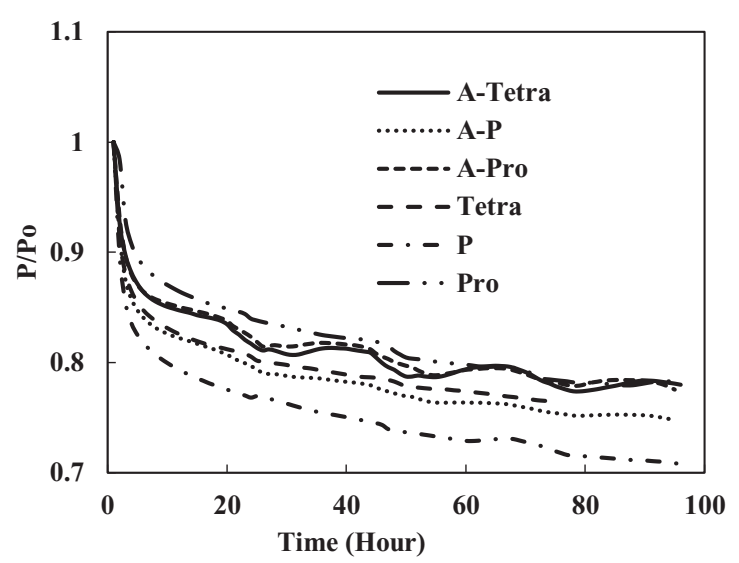

Figure 22. Swelling effect of acetone-prepared (A-) and non-prepared fluorosilicone O-ring in SPK fuel blends of single-species aromatics with $8 \%$ vol.

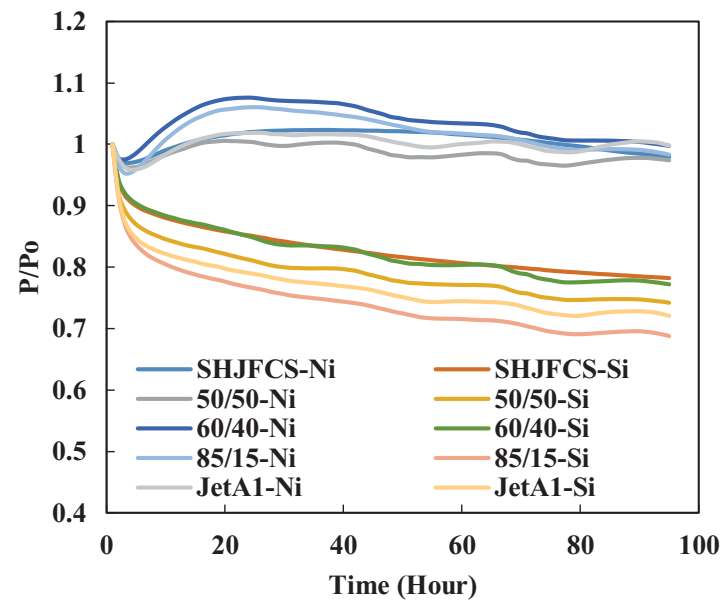

Figure 23. O-ring swell in Jet-A1 and SHJFCS mixture.

Five different compositions of the mixture were tested. As seen in Fig. 23, only nitrile O-rings swelled. This is further confirmed in Fig. 24, where all of them started with extraction, followed by swelling and then extraction once again. The chemical component in SHJFCS allowed the elastomers to swell. The same case goes for Jet-A1. No swelling occurred in fluorosilicone O-rings (Fig. 25).

Meanwhile, the highest maximum value of $\mathrm{P} / \mathrm{P}_{\mathrm{o}}$ was obtained by the nitrile $\mathrm{O}$-ring in the mixture of $60 / 40$, while the lowest was obtained by all the fluorosilicone O-rings with a value of 1 . It can be concluded that the optimum mixture of Jet-A1 and SHJFCS is a 60/40 ratio of the total volume percentage. The blending of SHJFCS and Jet-A1 causes the aromatic hydrocarbon from both fuels to interact. The maximum $\mathrm{P} / \mathrm{P}_{\mathrm{o}}$ values for $60 / 40$ and $85 / 15$ blends were higher than those of SHJFCS and Jet-A1.

However, the maximum $\mathrm{P} / \mathrm{P}_{\mathrm{o}}$ value for the $50 / 50$ blend was lower than that of both $\mathrm{SHJFCS}$ and Jet-A1, and the maximum $\mathrm{P} / \mathrm{P}_{\mathrm{o}}$ value for the $85 / 15$ blend was lower than that of the $60 / 40$ 


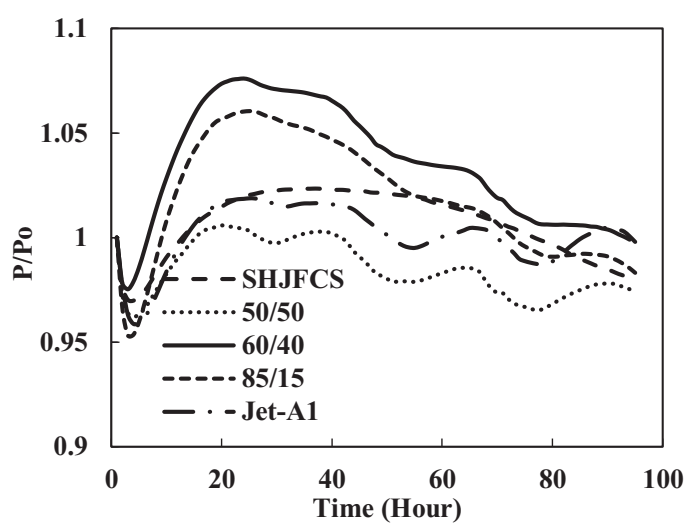

Figure 24. Nitrile O-ring swell in Jet-A1 and SHJFCS mixture.

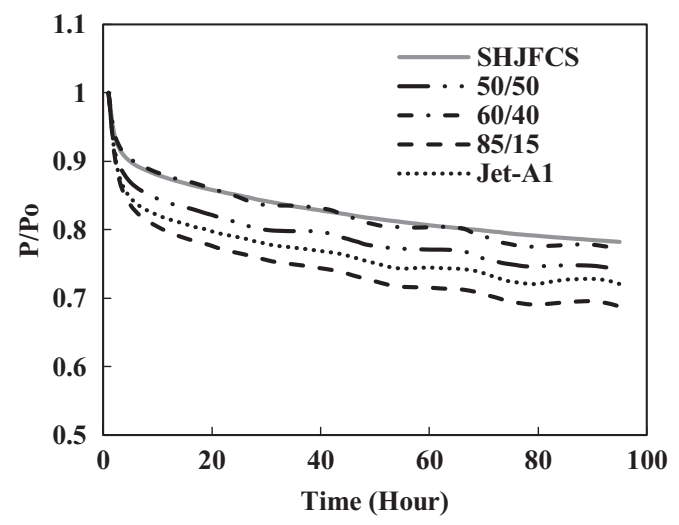

Figure 25. Fluorosilicone O-ring swell in Jet-A1 and SHJFCS mixture.

blend. It can be deducted that the optimum blend of SHJFCS and Jet-A1 ranges between $50 \%$ and $85 \%$ Jet-A 1 .

\subsection{CONCLUSIONS}

The use of synthetic fuel in the airline industry has started to become a trend. It started with a trial but is now expanding towards a larger scale, because of its lower emissions than conventional jet fuel. Furthermore, the fuel can be produced from readily available sources such as plant and animal fats. However, its compatibility issue with seals restricts its use in jet engine. Thus, the current research helps to understand the swelling effect of different elastomers in different fuels. It was observed in all tests that only nitrile seals exhibited a better response to swelling, while fluorosilicone O-rings were more prone to shrinking. Results show that the swelling effect for Jet-A1 was the highest, then followed by SHJFCS and SPK, respectively. It was confirmed from TC-1 and TC-2 that a higher volume of aromatic content in a fuel results in a higher rate of seal swelling. 
However, swelling rate does not depend solely on aromatics concentration but also on type of aromatics within the fuel. Meanwhile, the optimum blending percentage of Jet-A1 and SHJFCS from TC-4 was $60 \%$ Jet-A1 and $40 \%$ SHJFCS. The results show a linear relationship between rate of seal swelling and fuel's total aromatic concentration and type of fuel. Overall, this research has allowed some inferences regarding seal swell. Since more synthetic fuels are being created every day, more tests need to be conducted to determine their compatibility with seals in engines.

It can be observed that there were no colour changes at any of the elastomers at any point in the test. Besides, no cracking or peeling of the elastomers was observed. In addition, the seals were not physically damaged. From all the results collected, only nitrile O-rings exhibited a good response to swelling. This is in line with the findings of Muzzell et al. ${ }^{(4)}$, who also indicated that nitrile elastomers are very sensitive to changes in fuels and aromatics, unlike fluorosilicone elastomers. Thus, extensive future research is needed to achieve the target of producing renewable fuels that not only save the environment but also work well in engines.

The current work contributes to existing research in determining the right amount of aromatic content in the fuel by examining various aromatic percentages, that is, $4 \%, 8 \%, 12.5 \%$ and $25 \%$. Also, different types of aromatic species and their mixture fuel are selected. In the study, three aromatics, that is, tetralin, propyl benzene, and $p$-xylene, are investigated. With the above, various proportions of fuel blends with JetA-1 of $0 / 100,15 / 85,40 / 60,50 / 50$ and their combination with aromatics is also investigated. The primary aim of the study was to understand the behaviour of acetone-prepared and non-prepared seals, and their compatibility with alternative fuels.

\section{ACKNOWLEDGMENTS}

Testing was done at Low Carbon Combustion Centre of The University of Sheffield, UK.

\section{REFERENCES}

1. Hileman, J.I. and Stratton, R.W. Alternative jet fuel feasibility, Transport Policy, July 2014, 34, pp 52-62.

2. EwING, D. Alternative seals for alternative fuels, aero-online.org, June 2011, pp 27-30.

3. Hemighaus, G. Synthetic fuels for aviation, ASTM Standardization News, April 2007.

4. Muzzell, P., Stavinoha, L.L. and Rebeeca, C. Synthetic Fischer-Tropsch (FT) JP-5/JP-8 aviation turbine fuel elastomer compatibility, Technical Report, No 15043, 2005.

5. Liu Y. and Christopher, W.W. Investigation into the impact of n-decane, decalin, and isoparaffinic solvent on elastomeric sealing materials, Advances in Mechanical Engineering, 2012, pp 1-13.

6. Graham, J.L., Rahmes, T.F., Kay, M.C., Belieres, J.P., Kinder, J.D., James D., Millet, S.A., Ray, J. and VANNICE, W.L. Impact of alternative jet fuel and fuel blends on non-metallic materials used in commercial aircraft fuel systems, CLEEN Project Final Report - Submitted by The Boeing Company, 2011.

7. Matthew, D.J., Edwin, C., Graham, J. and Minus, D. Effects of aromatic type and concentration in Fischer-Tropsch fuel on emissions production and material compatibility, Energy and Fuels, 2008, 22 (4), pp 2411-2418.

8. Thomas, E.W., Fuller, R.E. and Terauchi, K. Fluoro elastomer compatibility with biodiesel fuels, SAE Technical Paper, 2007-01-4061, 2007.

9. Qamar, S.Z., Akhtar, M., Pervez, T. and Al-Kharusi, M.S.M. Mechanical and structural behavior of a swelling elastomer under compressive loading, Materials and Design, 2013, 45, pp 487-496.

10. Treloar, L.R.G. The elasticity and related properties of rubbers, Reports on Progress in Physics, 1973, 36, (7), pp 755-782. 
11. Baltrus, J.P., Link, D.D., Zandhuis, P.H., Gormley, R.J. and Anderson, R.R. Screening of potential O-ring swelling additives for ultraclean transportation fuels, Conference: Ultra Clean Transportation Fuels Symposium held at 230th ACS National Meeting, 2007. Vol. 959.

12. Graham, J.L., Striebich, R.C., Minus, D.K. and Harrison, W.E. The swelling of selected O-ring materials in jet propulsion and Fischer-Tropsch fuels, American Chemical Society. Division of Petroleum Chemistry, 2004, 49, (4), pp 435-439.

13. Anderson, D. The aromatic content of synthetic aviation fuels: how low can you go, Research Councils UK Impact Report, 2011.

14. Sptenz, G. Stress relaxation: test methods, instruments and lifetime estimation, Technical report 98/1, Elastocon AB, Sweden, 5th ed, 2015. https://www.elastocon.com/images/pdf/technicalreports/r-stress-relaxation.pdf

15. Panidi, I.S., Trofimov, V.A. and Lepiknina, N.S. Calculation of the molar volume of liquid hydrocarbons, Chemistry and Technology of Fuels, 2006, 42, (6), pp 440-445.

16. Frame E. and McCormick, R.L. Elastomer compatibility testing of renewable diesel fuels, Technical Report NREL. 2005.

17. Boyce, M.C. and Arruda, E.M. Swelling and mechanical stretching of elastomeric materials, Mathematics and Mech Solids, 2001, 6, (6), pp 641-659.

18. Liu, Y. Investigation on elastomer compatibility with alternative aviation fuels, The University of Sheffield, 2013. http://etheses.whiterose.ac.uk/4829/1/Thesis\%20Yue\%20Liu.pdf

19. Wijesinghe, C. and Khandelwal, B. Impact of aromatic species selection and micro and bulk properties of alternative fuels on atomization. Aeronautical Journal, 2021, pp 1-21.

20. Corporan, E., Edwards, T., Shafer, L., DeWitt, M.J, Klingshirn, C., Zabarnick, S., West, Z., Striebich, R., Graham, J. and Klein, J. Chemical, thermal stability, seal swell, and emissions studies of alternative jet fuels, Energy and Fuels, 2011, 25, (3), pp 955-966.

21. Sharma, S., Singh, P., Almohammadi, B.A., Khandelwal, B. and Kumar S. Testing of formulated fuel with variable aromatic type and contents in a compression-ignition engine. Fuel Processing Technology, 2020, 208, 106413.

22. Almohammadi, B.A., Singh, P., Sharma, S., Kumar, S. and Khandelwal, B. Impact of alkylbenzenes in formulated surrogate fuel on characteristics of compression ignition engine. Fuels, 2020, 266, 116981.

23. Singh, P., Sharma, S., Almohammadi, B.A., Kumar, S. and Khandelwal, B. Experimental investigation of aromatic blended binary fuel on pollutant emissions from compression ignition engine, In National Conference on IC Engines and Combustion, Springer, Singapore, 2019 Nov 1, pp 73-81.

24. Singh, P., Sharma, S., Almohammadi, B.A., Khandelwal, B. and Kumar, S. Applicability of aromatic selection towards newer formulated fuels for regulated and unregulated emissions reduction in CI engine. Fuel Processing Technology, 2020, 209, 106548.

25. Zheng, L., Ling C, Ubogu EA, Cronly J, Ahmed I, Zhang Y and Khandelwal B.. Alternative fuel properties' effects on particulate matter produced in a gas turbine combustor. Energy and Fuels, 2018, 32, (9), pp 9883-9897.

26. Khandelwal B, Wijesinghe CJ and Sriraman S. Effect of alternative fuels on emissions and engine compatibility, In: Runchal A., Gupta A., Kushari A., De A., Aggarwal S. (eds) Energy for Propulsion, Green Energy and Technology, Springer, Singapore, 2018, pp 27-50. https://doi.org/10.1007/978-981-10-7473-8_2.

27. Khandelwal, B., Cronly, J., Ahmed, I.S., Wijesinghe, C.J. and Lewis, C. The effect of alternative fuels on gaseous and particulate matter $(\mathrm{Pm})$ emission performance in an auxiliary power unit (APU), Aeronautical Journal, 2019, 123, pp 617-634. 